\title{
Videothoracoscopic talc poudrage in primary spontaneous pneumothorax: A single-institution experience in 861 cases
}

Giuseppe Cardillo, MD, FETCS, ${ }^{\mathrm{a}}$ Francesco Carleo, MD, ${ }^{\text {a }}$ Roberto Giunti, MD, ${ }^{\text {a }}$ Luigi Carbone, MD, ${ }^{\text {a }}$ Salvatore Mariotta, MD, ${ }^{\mathrm{c}}$ Lorenzo Salvadori, MD, ${ }^{\mathrm{a}}$ Lea Petrella, $\mathrm{PhD},{ }^{\mathrm{b}}$ and Massimo Martelli, MD ${ }^{\mathrm{a}}$

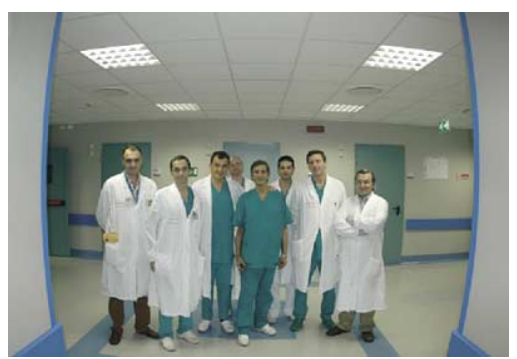

S. Treggiari, G. Cardillo, R. Giunti, L. Salvadori, M. Martelli, M. DiMartino, L. Carbone, M. Lopergolo. (left to right)
From the Thoracic Surgery Unit, Carlo Forlanini Hospital, Azienda Ospedaliera San Camillo-Forlanini, ${ }^{\text {a }}$ the Department of "Studi Geoeconomici, Linguistici, Statistici, Storici per l'Analisi Regionale," and the Department of Pneumology, S. Andrea Hospital, ${ }^{c}$ Medicine University of Rome "La Sapienza," Rome, Italy.

Read at the Eighty-fifth Annual Meeting of The American Association for Thoracic Surgery, San Francisco, Calif, April 10-13, 2005.

Received for publication April 8, 2005; revisions received Oct 11, 2005; accepted for publication Oct 20, 2005.

Address for reprints: Giuseppe Cardillo, MD, The Thoracic Surgery Unit, Carlo Forlanini Hospital-Via Portuense 332, 00149 Rome, Italy (E-mail: gcardillo@ scamilloforlanini.rm.it).

J Thorac Cardiovasc Surg 2006;131:322-8

$0022-5223 / \$ 32.00$

Copyright (C) 2006 by The American Association for Thoracic Surgery

doi:10.1016/j.jtcvs.2005.10.025
Objective: We sought to evaluate the outcome of 861 patients treated with videothoracoscopic talc poudrage for primary spontaneous pneumothorax.

Methods: From September 1995 through January 2004, a total of 861 patients (578 male, 283 female, mean age 28.6 years) underwent videothoracoscopy for recurrent and complicated primary spontaneous pneumothorax. Patients were treated with videothoracoscopic talc poudrage only (group A: Vanderschueren's stage I, 196 patients; stage II, 112 patients) or videothoracoscopic talc poudrage plus stapling of the blebs/bullae (group B: stage III, 391 patients; stage IV 162 patients). Follow-up included clinical interview and chest radiography (805 patients). In 26 patients (follow-up longer than 5 years), respiratory function was investigated to determine residual volume and diffusing lung capacity.

Results: No operative deaths occurred. No patient had adult respiratory distress syndrome. Postoperative complications occurred in 29 patients $(3.36 \%)$. The conversion rate to an open procedure was $0.46 \%$ (4/861). After a mean follow-up of 52.5 months, 14 patients had recurrences $(1.73 \%)$. The recurrence rate was $2.41 \%$ $(7 / 290)$ in group A and $1.359 \%$ (7/515) in group B ( $\chi^{2}$ value: $1.207389 ; P: .27$; odds ratio: 0.56 ; $95 \%$ confidence interval: $0.20-1.62$ ). Results of respiratory function tests were within normal ranges ( $80 \%$ or more of predictive value) in all 26 patients.

Conclusions: Videothoracoscopic talc poudrage achieves a high success rate in the treatment of primary spontaneous pneumothorax with a very low morbidity rate. Recurrences show a statistically significant relationship (P:.037) with smoking habits.

$\mathrm{P}$ rimary spontaneous pneumothorax (PSP) is a significant global problem occurring in otherwise healthy young subjects with a reported incidence of 18 to 28 cases per 100,000 population per year for men and 1.2 to 6 cases per 100,000 population per year for women. ${ }^{1,2}$ Smoking plays a role in the development of $\mathrm{PSP}^{3}$ : the lifetime risk in healthy smoking men may be as much as $12 \%$ compared with $0.1 \%$ in nonsmoking men. ${ }^{3}$ PSP recurs in up to $25 \%$ of the cases after a first episode and up to $50 \%$ after a second episode, especially in the first 2 years after the initial episode. ${ }^{4}$ Treatment options for PSP include observation, manual aspiration, intercostal tube drainage, and surgery. ${ }^{1,2,4}$

There is clear evidence that patients with a first episode of PSP should be treated with intercostal drainage in most cases and with observation or manual aspiration in a very few selected cases. The surgical option should be offered in case of a second ipsilateral pneumothorax, first contralateral pneumothorax, bilateral spontaneous pneumothorax, spontaneous hemothorax, persistent air leak ( $>5-7$ days of tube drainage), failure to completely re-expand after intercostal drainage, and for professions at risk (aircraft personnel, sportsmen, scuba divers). ${ }^{1,2}$ 


\section{Abbreviations and Acronyms \\ PSP = primary spontaneous pneumothorax \\ VATS $=$ videothoracoscopy}

Surgical options include open thoracotomy with bleb resection and pleurectomy or videothoracoscopy (VATS) with bleb resection plus pleural abrasion or talc pleurodesis. A recent review by Sedrakyan and associates ${ }^{5}$ comparing only randomized trials found VATS to be associated with a shorter length of hospital stay or use of pain medication than thoracotomy, with a comparable complication profile and success rate. As regards as the method of choice for obtaining pleurodesis, most authors ${ }^{6,7}$ prefer parietal pleurectomy or pleural abrasion, although some concern still exists with talc poudrage either because of the potential side effects of talc or because of a reported relatively high failure rate.

In this article we evaluate the short- and intermediateterm results of 861 patients treated with VATS talc poudrage for PSP in a 9-year period. A special emphasis is paid to side effects of the talc.

\section{Methods}

From September 1, 1995, to January 30, 2004, out of 2956 VATS operations performed at the Unit of Thoracic Surgery, Carlo Forlanini Hospital in Rome, 861 patients $(29.12 \%)$ underwent VATS treatment of PSP. No patient with HIV infection or cystic fibrosis is included in the present series. Patient characteristics are shown in Table 1 . The diagnosis was made by conventional chest radiographs. In 92 cases $(10.68 \%)$ chest high-resolution computerized tomography scans were performed. Preoperative investigation included complete blood cell count, renal function tests, and electrocardiograms. Indications for surgery are shown in Table 2. Intraoperative staging was done according to Vanderschueren's classification $^{8}$ : stage I, no endoscopic abnormalities; stage II, pleuropulmonary adhesions; stage III, blebs/bullae less than $2 \mathrm{~cm}$; stage IV, bullae more than $2 \mathrm{~cm}$. The surgical protocol was as follows: stage I, talc poudrage only; stage II, lysis of all adhesions and talc poudrage; stages III and IV, stapling of the blebs/bullae plus talc poudrage. Talc was selected according to the Italian

TABLE 1. Patients characteristics

\begin{tabular}{lcc}
\hline & No. & $\%$ \\
\hline Total patients & 861 & 100 \\
$\quad$ Male & 578 & 67.13 \\
$\quad$ Female & 283 & 32.87 \\
Mean age (y) & 28.6 & \\
Median age (y) & 28 & \\
Range (y) & $12-49$ & 59.35 \\
Smokers & 511 & 70.64 \\
Male smokers & 361 & 17.42 \\
Female smokers & 150 & \\
\hline
\end{tabular}

TABLE 2. Indications for surgery

\begin{tabular}{lc}
\hline & No. of patients \\
\hline Ipsilateral recurrent pneumothorax & 792 \\
Persistent air leak after intercostal drainage & 23 \\
Failure to completely re-expand after & 21 \\
$\quad$ intercostal drainage & \\
Hemopneumothorax & 11 \\
First contralateral pneumothorax & 9 \\
Bilateral spontaneous pneumothorax & 4 \\
Professions at risk & 1 \\
\hline
\end{tabular}

standards (Farmacopea Italiana Ufficiale): (length of the fibers $<$ $50 \mu \mathrm{m})$. After surgery, patients underwent clinical interview and chest radiography in our outpatient clinic at 1 month, 3 months, and every 12 months postoperatively up to November 30, 2004.

Patients were asked to subjectively grade the severity of any residual paresthesia (defined as any numbness or disordered sensation causing chest wall discomfort that was distinguishable from normal postoperative wound pain) on a 10-point analog scale (with 1 being minimal discomfort and 10 being the worst discomfort imaginable): paresthesia was graded as mild (1-3), moderate (4-7), and severe $(8-10){ }^{9}$

Recurrent pneumothorax is defined as a pneumothorax greater than $10 \%$ of the hemithorax in size. Twenty-six patients with no recurrences underwent pulmonary function tests to evaluate forced expiratory volume in 1 second, vital capacity, residual volume, Tiffenau index, residual volume/total lung capacity, and diffusing capacity for carbon monoxide by single breath test.

The research was approved by the Institutional Review Board of Carlo Forlanini Hospital and informed consent was obtained from each patient.

\section{Statistical Analysis}

Data were analyzed with NCSS 2004 (Number Cruncher Statistical Systems, Kaysville, Utah). The $\chi^{2}$ test was used to ascertain the significance of association between two categorical variables. The unpaired Student $t$ test was used to assess the significance between the mean of patients' age with or without recurrence of disease. The FarringtonManning test was performed to compute the confidence intervals and hypothesis tests for the odds ratio. The overall freedom from recurrence in the two groups A and B was estimated by Kaplan-Meier survival curves and differences by the log-rank test.

\section{Operative Technique}

All operations were performed with the patient under general anesthesia using a double-lumen endotracheal Carlens tube and one-lung ventilation. The patient was placed and prepared as for a posterolateral thoracotomy. The first incision was always placed below the tip of the scapula in the fifth or sixth intercostal space. A 0 -degree, $10 \mathrm{~mm}$ videothoracoscope was introduced through a thoracoport. One or two other thoracoports were placed under endoscopic guid- 
TABLE 3. Recurrences according to Vanderschueren's stage

\begin{tabular}{lccc}
\hline Stage of PSP & No. & Patients at follow-up & Recurrence (\%) \\
\hline Stage I & 196 & 181 & $4(2.18 \%)$ \\
Stage II & 112 & 109 & $3(2.75 \%)$ \\
Stage III & 391 & 367 & $5(1.36 \%)$ \\
Stage IV & 162 & 148 & $2(1.35 \%)$
\end{tabular}

$P S P$, Stage of pneumothorax.

ance. Carbon dioxide was never necessary to enlarge the spontaneous pneumothorax. The lung was inspected during gentle ventilation with saline in the pleural cavity to detect blebs/bullae and air leaks. Blebs/bullae were treated by minimal wedge resection with the endoscopic stapler (SCB 45, Ethicon Endosurgery, Cincinnati, Ohio). In case of minimal air leak or bleeding along the suture line, fibrin glue was used (Tissucol; Baxter, Deerfield, Mass). Talc poudrage was accomplished by nebulization in the pleural cavity of $2 \mathrm{~g}$ of asbestos-free sterilized talc.

\section{Results}

There were no postoperative (30-day) deaths. No intraoperative complications were reported. No patient required blood transfusion. Mean operative time was $14 \pm 8$ minutes. The conversion rate to an open procedures was $0.46 \%$ (4/861 cases). The reason for conversion was extensive pleural adhesions with obliteration of the pleural cavity. Staging according to Vanderschueren's classification was as follows: stage I, 196 patients (22.76\%); stage II, 112 patients (13.0\%); stage III, 391 patients (45.41\%); and stage IV, 162 patients $(18.81 \%$ ) (Table 3). The postoperative complication rate was $3.36 \%$ (29/861 cases). It included localized pleural effusion (15 cases), prolonged air leaks ( $>5$ days) (9 cases), subcutaneous emphysema (3 cases), pneumonia (1 case), and transient Bernard-Horner syndrome (1 case). All complications resolved spontaneously. Mean time to removal of chest tubes was 4.7 days (range 4-10 days). Mean hospital stay was 5.6 days (range 4-12 days). At discharge from the hospital, a moderate-to-severe paresthesia was described by 114 patients (13.24\%). Shortterm follow-up (1 month) was available in all 861 patients $(100 \%)$. At 1 month after the operation, only 16 patients (1.85\%) described paresthesia as being moderate to severe. Paresthesia spontaneously resolved in all patients within 6 months after the operation. A total of 564 (65.5\%) patients had returned to occupational activities within 21 days and $786(91.28 \%)$ patients within 30 days. An intermediate-term follow-up was completed in $805(93.49 \%)$ patients. The mean follow-up was 52.5 months (range 10-110 months). A follow-up longer than 60 months was available for 285 patients. The overall recurrence rate was $1.73 \%$ (14/805). Among 805 patients included in the follow-up, mean age
TABLE 4. Patients lost to follow-up or having a recurrence at each follow-up time point

\begin{tabular}{|c|c|c|c|c|c|c|c|c|c|c|c|c|}
\hline Time points (mo) & 1 & 3 & 12 & 24 & 36 & 48 & 60 & 72 & 84 & 96 & 108 & $\begin{array}{c}\text { Total } \\
\text { patients } \\
\text { (\#) }\end{array}$ \\
\hline $\begin{array}{l}\text { No. of patients } \\
\text { with recurrent } \\
\text { PT }\end{array}$ & 0 & 0 & 2 & 10 & 1 & 1 & 0 & 0 & 0 & 0 & 0 & 14 \\
\hline $\begin{array}{l}\text { No. of patients } \\
\text { lost to FUP }\end{array}$ & 0 & 12 & 9 & 7 & 8 & 13 & 7 & 0 & 0 & 0 & 0 & 56 \\
\hline
\end{tabular}

$P T$, Pneumothorax; FUP, follow-up.

was 28.12 years in patients in whom PSP did not recur and 29.71 years in patients in whom it did recur (P.75). Patients were divided into two groups according to the surgical treatment: group A (talc poudrage only, stages I and II, 290 patients) and group B (talc poudrage plus stapling of the blebs/bullae, stages III and IV, 515 patients) (Table 2). The 8-year freedom from recurrence was $96.87 \%$ and $98.61 \%$, respectively, in group A and group B; difference calculated by log-rank test was not significant $(P .10)$. The recurrence rate was $2.41 \%(7 / 290)$ in group A and $1.359 \%(7 / 515)$ in group B ( $\chi^{2}$ value1.207389; P.27; odds ratio $0.56 ; 95 \%$ confidence intervals $0.20-1.62$ ). Data regarding patients passing each follow-up time point and patients lost to follow-up or having a recurrence at each time point are shown in Table 4 and Figure 1.

With regard to smoking, 12 recurrences occurred in smokers (12/471 [2.54\%]) and 2 occurred in nonsmokers $(2 / 334[0.598 \%])\left(\chi^{2}\right.$ value $4.343785 ; P .037$; odds ratio 0.24 ; $95 \%$ confidence intervals $0.06-0.93$ ). Recurrences occurred within 12 months in 2 patients (stage IV and stage I), between 12 and 24 months in 10 patients (stage I: 3; stage

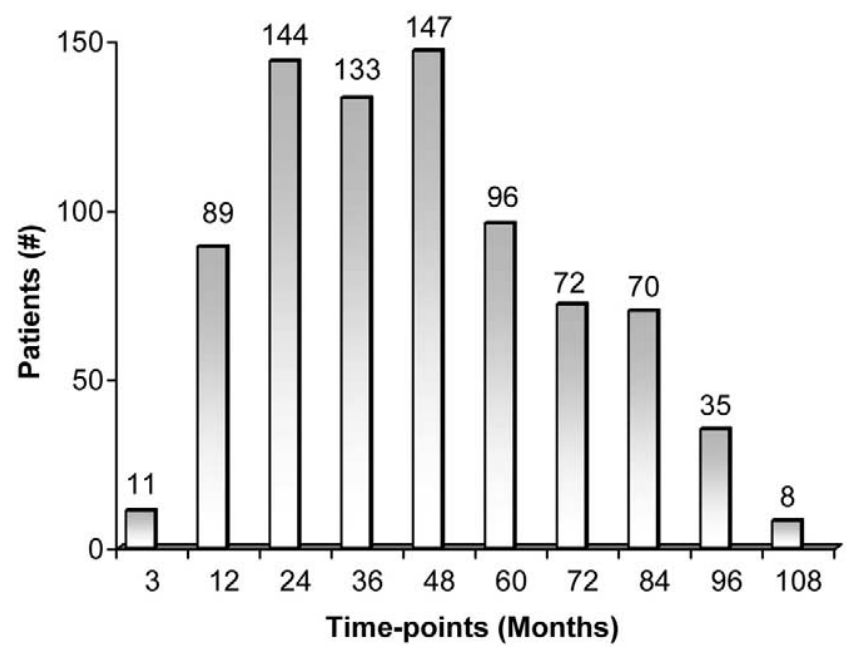

Figure 1. Maximum time-point follow-up for each of the 805 patients with a complete follow-up. 
TABLE 5. Recurrence rates in studies of VATS treatment of PSP

\begin{tabular}{llcccl}
\hline First author & Year & No. & Follow-up (mo) & Recurrence (\%) & Pleurodesis \\
\hline Present experience & 2005 & 805 & 52.5 & 1.73 & Talc poudrage \\
Ayed7 & 2003 & 100 & 48 & 2 & Pleurectomy \\
Gossot23 & 2003 & 111 & 36.5 & 3.6 & Pleural abrasion \\
Lang-Lazdunski14 & 2003 & 167 & 84 & 3 & Pleural abrasion \\
Margolis18 & 2003 & 156 & 62 & 0 & Cautery + talc poudrage \\
Tschopp19 & 2002 & 59 & 38 & 5 & Talc poudrage \\
Cardillo16 & 2000 & 432 & 4.4 & Pleurectomy/talc poudrage
\end{tabular}

VATS, Videothoracoscopy; PSP, primary spontaneous pneumothorax.

II: 2; stage III: 4; stage IV: 1 ), and after 29 months and 38 months, respectively, in the remaining 2 patients (stage II and stage III) (Tables 4 and 5). Recurrences were loculated in 11 patients $(78.57 \%)$, almost total in 3 patients, and were treated by re-VATS (9 cases), chest drainage (3 cases), and observation (2 cases).

Twenty-six patients (15 male, 11 female) with a follow-up longer than 60 months underwent respiratory function tests: forced expiratory volume in 1 second, forced vital capacity, and diffusing capacity for carbon monoxide were within normal ranges $(80 \%$ or more than predictive value) in all 26 patients.

\section{Discussion}

PSP typically occurs in young male adults with a peak age incidence of 20 to 30 years. ${ }^{1,2}$ Additional risk factors are cigarette smoking and an asthenic physiognomy. ${ }^{3}$ No precipitating causes can usually be identified. Most episodes occur at rest. The role of atmospheric pressure or weather changes is unclear. ${ }^{10,11}$ Recurrences as well as first contralateral pneumothorax, bilateral spontaneous pneumothorax, spontaneous hemothorax, persistent air leak ( $>5-7$ days of tube drainage) or failure to completely re-expand after drainage of intercostals, and professions at risk are clear indications for surgery. ${ }^{4}$ There is still a matter of debate regarding the type of surgery. The great majority of the last reported papers favor the minimally invasive VATS approach even if, comparing randomized trials, VATS can only be associated with shorter length of hospital stay or use of pain medication than thoracotomy with a comparable complication profile and success rate. ${ }^{5}$ An obvious better cosmetic result has also been claimed by most authors. ${ }^{4}$ Some authors report that chronic pain can still afflict up to $63 \%$ of patients after VATS pleurodesis. ${ }^{12-15}$ Paresthesia resolved spontaneously in almost all patients: in our series, 114 patients (13.24\%) described moderate-to-severe paresthesia at discharge from the hospital, but only 16 patients $(1.85 \%)$ at 1 month, and nobody described residual paresthesia 6 months after the operation. ${ }^{9}$ As previously reported, ${ }^{16}$ most recurrences occur within 2 years from surgery: this interval should be regarded as the high-risk window for patients treated for pneumothorax.

In the light of our previous reported experiences ${ }^{4,16}$ and of the results reported in the present series, we believe VATS to be an excellent technique for the treatment of recurrent and complicated PSP and talc poudrage to be the preferred tool for inducing pleurodesis (Table $5)$.

The overall recurrence rate reported in our series (1.73\%) is much less than the $9 \%$ reported by Kennedy and Sahn ${ }^{17}$ in a meta-analysis published in 1994. Most recent articles $^{4,18-23}$ dealing with VATS treatment of PSP have reported a lower failure rate ranging from $0 \%$ to $5 \%$ (Table 5). These results are comparable with the failure rate $(0.4 \%$ $0.5 \%$ ) reported with standard thoracotomy or transaxillary minithoracotomy. ${ }^{20-22}$ There are no data to assess the optimal dosage schedule of talc. The reported dosage ranges from 2 to $10 \mathrm{~g}$. There are no controlled trials to state that higher dosages of talc are more effective in inducing pleurodesis. $^{2}$ In our experience, we nebulized in the pleural cavity $2 \mathrm{~g}$ of talc and we believe there is no reason to use a higher dosage of talc with such technique. ${ }^{4,16}$

With regard to the concern with the use of talc in young patients, we believe that oncologic risk can be excluded reasonably by the use of asbestos-free talc according to a survey of Chappel, ${ }^{24}$ and coauthors. The risk of adult respiratory distress syndrome (ARDS) claimed by some authors ${ }^{25}$ has not been confirmed in our series of 861 patients treated in a 9-year period. The risk may be related to the size of talc particles. ${ }^{5}$ The Italian standard (length of fibers $<50 \mu \mathrm{m}$ ) seems to be a protective factor for ARDS. Empyema, never reported in our experience, may be related to technique used for the sterilization of talc. ${ }^{19,26}$ Respiratory failure has never been observed in our series: clinical follow-up did not reveal any case of respiratory failure in the overall series of 805 patients included in the follow-up. Furthermore, pulmonary function tests were within normal ranges in a group of 26 patients with a follow-up longer than 5 years. The concern regarding the potential long-term (up to 35 years) effect of talc poudrage on a young person has been 
addressed by Lange, Mortenson, and Groth ${ }^{27}$ in a group of 75 patients: they showed only a mild restrictive respiratory impairment at a follow-up of 22 to 35 years. Regarding the issue of future thoracic surgery in these patients, we believe that re-entering the chest will be a big problem either after talc poudrage or after pleurectomy/pleural abrasion. Minor postoperative complications $(3.36 \%)$ were reported. Such rate appears to be much lower than the $10 \%$ complication rate reported by the largest series dealing with transaxillary minithoracothomy. ${ }^{22}$ The reasons for such a good success rate of our technique are the great number of surgically treated patients (861 patients), as to our knowledge this experience represents the largest published series of surgically treated PSP in the world literature; the small number of surgeons (100\% of the procedures were performed by 3 consultant thoracic surgeons, M.M., R.G., G.C.); the absence of a learning curve (our experience with VATS treatment of pneumothorax started much earlier); the homogeneity of the technique; and the efficacy of talc in inducing pleurodesis. The short operative time $(14 \pm 8$ minutes) reported in the present series, not changed by additional procedures such as stapling or lysis of adhesions, represents an additional protective factor for a low complication rate. The recurrences showed a statistically significant relationship with smoking habits of the patients: $2.54 \%$ recurrence rate in smokers versus $0.598 \%$ in nonsmokers (P.037). Some authors ${ }^{28,29}$ perform blind apical stapling in patients with no evidence of bullae (stages I and II). It is our policy to perform only pleurodesis in such patients, and our data confirm this thesis.

Recurrences after VATS talc poudrage are usually loculated and can be managed either by conservative approach or by redo VATS. ${ }^{16}$

In conclusion, VATS talc poudrage shows a high success rate $(98.27 \%)$ in the treatment of PSP with a very low morbidity rate $(3.36 \%)$. Recurrences show a statistically significant relationship ( $P$.037) with smoking habits, so that counseling regarding smoking cessation ideally should be undertaken before and after surgery.

We thank Mrs Laura D'Orlando for performing respiratory functional studies, and Mrs Rita Pantini, thoracic theater head nurse.

\section{References}

1. Baumann MH, Strange C, Heffner JE, Light R, Kirby TJ, Klein J, et al. Management of spontaneous pneumothorax. ACCP Delphi Consensus Statement. Chest. 2001;119:590-602.

2. Henry M, Arnold T, Harvey J, on behalf of the BTS Pleural Disease Group, a subgroup of the BTS Standards of Care Committee. Thorax. 2003;58(Suppl II):ii39-ii52.

3. Bense L, Eklund G, Wiman LG. Smoking and the increased risk of contracting pneumothorax. Chest. 1987;92:1009-12.

4. Cardillo G, Facciolo F, Giunti R, Gasparri R, Lopergolo M, Orsetti R, et al. Videothoracoscopic treatment of primary spontaneous pneumo- thorax: a 6-year experience. Ann Thorac Surg. 2000;69:357-61; discussion 361-2.

5. Sedrakyan A, van der Meulen J, Lewsey J, Treasure T. Video assisted thoracic surgery for treatment of pneumothorax and lung resections: systematic review of randomised clinical trials. BMJ. 2004;329:1008. Epub 2004 September 22.

6. Torresini G, Vaccarili M, Divisi D, Crisci R. Is video-assisted thoracic surgery justified at first spontaneous pneumothorax? Eur J Cardiothorac Surg. 2001;20:42-45.

7. Ayed AK. Suction vs water seal after thoracoscopy for primary spontaneous pneumothorax: prospective randomized study. Ann Thorac Surg. 2003;75:1593-6.

8. Vanderschueren RGJRA. Le talcage pleural dans le pneumothorax spontane. Poumon-Coeur. 1981;37:273-6.

9. Sihoe ADL, Au SSW, Cheung ML, Chow IKL, Chu KM, Law CY, et al. Incidence of chest wall paresthesia after video-assisted thoracic surgery for primary spontaneous pneumothorax. Eur J Cardiothorac Surg. 2004;25:1054-8.

10. Scott GC, Berger R, McKean HE. The role of atmospheric pressure variation in the development of spontaneous pneumothoraces. Am Rev Respir Dis. 1989;139:659-62.

11. Smit HJM, Deville WL, Schramel FMNH, Schreurs AJM, Sutedja TG, Postmus PE. Atmospheric pressure changes and outdoor temperature changes in relation to spontaneous pneumothorax. Chest. 1999;116: 676-81.

12. Mouroux J, Elkaim DJ, Padovani B, Myx A, Perrin C, Rotomondo C, et al. Video-assisted thoracoscopic treatment of spontaneous pneumothorax: techniques and results of one hundred cases. $J$ Thorac Cardiovasc Surg. 1996;112:385-91.

13. Bertrand PC, Regnard JG, Spaggiari L, Levi JF, Magdeleinat P, Guibert L, et al. Immediate and long-term results after surgical treatment of primary spontaneous pneumothorax by VATS. Ann Thorac Surg. 1996;61:1641-5.

14. Lang-Lazdunski L, Chapuis O, Bonnet PM, Pons F, Jancovici R. Videothoracoscopic bleb excision and pleural abrasion for the treatment of primary spontaneous pneumothorax: long-term results. Ann Thorac Surg. 2003;75:960-5.

15. Passlick B, Born CH, Sienel W, Thetter O. Incidence of chronic pain after minimal-invasive surgery for spontaneous pneumothorax. Eur J Cardiothorac Surg. 2001;19:355-9.

16. Cardillo G, Facciolo F, Regal M, Carbone L, Corzani F, Ricci A, et al. Recurrences following videothoracoscopic treatment of primary spontaneous pneumothorax: the role of redo-videothoracoscopy. Eur J Cardiothorac Surg. 2001;19:396-9.

17. Kennedy L, Sahn SA. Talc pleurodesis for the treatment of pneumothorax and pleural effusion. Chest. 1994;106:1215-22.

18. Margolis M, Gharagozloo F, Tempesta B, Trachiotis GD, Katz NM, Alexander P. Video-assisted thoracic surgical treatment of initial spontaneous pneumothorax in young patients. Ann Thorac Surg. 2003;76: 1661-4.

19. Tschopp JM, Brutsche M, Frey JG. Treatment of complicated pneumothorax by simple talc pleurodesis under thoracoscopy and local anaesthesia. Thorax. 1997;52:329-32.

20. O'Rourke JP, Yee ES. Civilian spontaneous pneumothorax: treatment options and long term results. Chest. 1989;96:1302-6.

21. Weedon D, Smith GH. Surgical experience in the management of spontaneous pneumothorax, 1972-1982. Thorax. 1983;38:737-43.

22. Deslauriers J, Beaulieu M, Després JP, Lemieux M, Leblanc J, Desmeules M. Transaxillary pleurectomy for treatment of spontaneous pneumothorax. Ann Thorac Surg. 1980;30:567-74.

23. Gossot D, Galetta D, Stern JB, Debrosse D, Caliandro R, Girard P, et al. Results of thoracoscopic pleural abrasion for primary spontaneous pneumothorax. Surg Endosc. 2004;18:466-71.

24. Chappel AG, Johnson A, Charles J, et al: A survey of the long-term effects of talc and kaolin pleurodesis. Br J Dis Chest. 1979; 73:285-8.

25. Rinaldo JE, Owens GR, Roger RM. Adult respiratory distress syndrome following intrapleural instillation of talc. $J$ Thorac Cardiovasc Surg. 1983;85:523-6.

26. Hamed H, Fentiman IS, Chaudary MA, Rubens RD. Comparison of bleomycin and talc for the control of pleural effusions secondary to carcinoma of the breast. Br J Surg. 1989;76:1266-7. 
27. Lange P, Mortenson J, Groth S. Lung function 22-35 years after treatment of idiopathic spontaneous pneumothorax with talc poudrage or simple drainage. Thorax. 1988;43:559-61.

28. Naunheim KS, Mack MJ, Hazerligg SR, Hazelrigg SR, Ferguson MK, Ferson PF, Boley TM, et al. Safety and efficacy of video-assisted thoracic surgical techniques for the treatment of spontaneous pneumothorax. J Thorac Cardiovasc Surg. 1995;109:1198-204.

29. Körner H, Andersen KS, Stangeland L, Ellingsen I, Engedal H. Surgical treatment of spontaneous pneumothorax by wedge resection without pleurodesis or pleurectomy. Eur J Cardiothorac Surg. 1996; 10:656-9.

\section{Discussion}

Dr Douglas E. Wood (Seattle, Wash). Dr Cardillo, first I would like to congratulate you and your colleagues for a well-done and impressive study with very large numbers and superb results.

Some surgeons have continued to question the efficacy of thoracoscopy for managing patients with SPS, but I think that the results of this paper demonstrate a very low complication rate and an even lower recurrence rate that matches or exceeds any other publications on this subject. Dr Cardillo, you have given evidence that strongly supports the practice of VATS bleb resection and pleurodesis for SPS, and I would expect that this is probably a technique favored by the majority of surgeons in this room. However, your study does not alleviate my concerns regarding the potential long-term effects of talc pleurodesis on young persons with several decades of life ahead of them. You did not show any ill effects for up to 9 years after the procedure, but do you have any information on the possible natural history of talc in the pleural space over 40, 50, or 60 years? Do you have any concern that a progressive restrictive fibrothorax may develop in these patients over longer periods of follow-up? Some percentage of these patients are also likely to require thoracic surgery in the distant future. Do you have any idea what findings or difficulty to predict for a future generation of thoracic surgeons trying to resect a lung cancer in one of these patients 40 years later?

I applaud your results, but I wonder whether you might be able to achieve equivalent or very similar results with mechanical pleurodesis and avoid the theoretical complications of talc in the pleural space over several decades. You have a high-volume center. Would it be possible to conduct a randomized trial to examine the difference between pleurodesis techniques?

Dr Cardillo. Thank you, Dr Wood. We have, of course, no idea regarding the very long-term effect of talc. This is a long-term study, but maximum follow-up is 100 months, which is still not enough. The function tests we have performed in patients with a long-term follow-up over 5 years showed that this is not really a restrictive disease. We have no preoperative data. We should compare the results of the pulmonary function tests with the standard of these patients. We have done this in a small series of patients and the results were within normal range. Obviously we are concerned about long-term results. Furthermore, in a small group we have performed high-resolution computed tomography as a follow-up (not discussed it in this paper), and we have not seen any impressive change. There was a thickening of the pleural line, but it was a very small thickening. We have observed this change in some patients who were willing to undergo computed tomography.
Regarding thoracic surgery in these patients, of course it will be a big problem in the future. However, we do not have to compare these patients with normal subjects. We have to compare patients who have had talc poudrage with patients who have undergone mechanical pleurodesis, such as pleural ablation or pleurectomy. In our opinion, there is not a big difference between opening the chest in a patient who underwent pleural ablation (and that means bleeding) or in a patient who underwent pleurectomy or talc poudrage.

Dr Allen. Could you do a randomized trial?

Dr Cardillo. That would be a good idea. However, if one compares the different techniques of pleurodesis up until now, the results in the literature seems to indicate that talc poudrage is preferable. Of course, if possible, a randomized study would be optimal.

Dr Carlos Saldarriaga (Medellin, Colombia). There were 283 women in your study. How many patients with catamenial pneumothorax or diaphragmatic pleural syndrome did you have in your series and how did you treat these patients?

Dr Cardillo. Catamenial pneumothorax has been occasionally found in our series. In these patients you have to carefully evaluate the diaphragm, looking for some endometrial tissue. Really, I think we have included only one or two patients with catamenial pneumothorax, but in our series we have not found in any patient endometrial tissue along the diaphragm or along the pleura.

Dr Malcolm M. DeCamp (Boston, Mass). I enjoyed your report very much. It is certainly a tremendous large-volume series that sort of dwarfs the other reports by threefold or fourfold.

I have two questions, the first pertaining to indications for the patients with persistent air leak. How long is persistent? How many days will you wait for an air leak to resolve before you would suggest surgery? Second, would you elaborate on the postoperative management? You said it was your practice in this retrospective series to leave the chest tubes for 4 or 5 days. What are the criteria now other than resolution of air leak before you will remove the chest tube?

Dr Cardillo. In our opinion, a leak persisting for 4 to 5 days is a long-term air leak. When we started our experience, we decided to wait at least 5 days before doing the operation in patients with an SPS, but with time we are changing our minds. Now we wait 4 and, in some cases, 2 days before doing the operation. If the lung is well inflated, then we can wait a little longer, but if the lung is not well inflated, even after 2 days, I think it is time for surgery.

Regarding the removal time, in accordance with a study of Dr Boutin, in the beginning we decided to leave the tube in place at least 5 days, even if the lung was well inflated and there was no air leak. Now I think we wait 4 days, but not less than 4 days. This is our rule.

Dr Walter Weder (Zurich, Switzerland). You did not mention as a possible concern that these talc fibers are found in all organs-in the brain, in the heart, in the muscle, in the kidneyand this has been shown in animal studies and in autopsies also. Is this not a concern for you? Do you inform these patients that these fibers go to all organs?

Dr Cardillo. Thank you, Dr Weder. Talc embolization was described by Dr West either in animals or in human beings in a 
recent paper that I cited in my presentation. Dr West published in the Current Opinion in Pulmonary Medicine in 2004 a paper regarding the issue of systemic embolization of talc. He works at the Oxford Pleural Diseases Unit in the United Kingdom, and he has a great experience: in his paper he wrote that the problem of systemic embolization is not yet clarified. So we do not know the ramifications. This problem may even be related to the diameter of the talc particles. When we have the results of the ongoing trial on the safety of talc, we will have more data to address this issue.

Dr David Waller (Leicester, United Kingdom). Dr Cardillo, you have shown that pleurectomy may not be needed to treat this condition. You have also shown that a third of the patients do not need resection of the blebs. What is your opinion of the treatment of this condition by pulmonologists by the so-called medical thoracoscopy?

Dr Cardillo. Thank you, Dr Waller.

In my country we do not let pulmonologists treat pneumothorax. Only thoracic surgeons are allowed to do thoracoscopy. I work in a hospital in which there are many pulmonologists. They do bronchoscopy, they do pleuroscopy, but we absolutely do not let them to do thoracoscopy. So we are the only doctors treating pneumothorax in my hospital. I do not know about other institutions.

\section{Online-www.aats.org}

Now you can get The Journal of Thoracic and Cardiovascular Surgery online. The Journal online brings you faster delivery time, easy searching of current and back issues, links to PubMed, AATS, WTSA, and other important sites, and more. Visit the Journal online today.

\section{Receive tables of contents by e-mail}

To receive the tables of contents by e-mail, sign up through our Web site at http://journals.elsevierhealth.com/periodicals/ymtc

Choose E-mail Notification

Simply type your e-mail address in the box and click the Subscribe button. You will receive an e-mail to confirm that you have been added to the mailing list.

Note that TOC e-mails will be sent out when a new issue is posted to the Web site. 